Article

\title{
Citrus aurantium L. Dry Extracts Ameliorate Adipocyte Differentiation of 3T3-L1 Cells Exposed to TNF $\alpha$ by Down-Regulating $m i R-155$ Expression
}

\author{
Michele Campitelli ${ }^{1,2,+}$, Antonella Desiderio ${ }^{1,2,+}$, Giuseppe Cacace ${ }^{1,2}$, Cecilia Nigro ${ }^{1,2}$, \\ Immacolata Prevenzano ${ }^{1,2}$, Alessia Leone ${ }^{1,2}$, Sonia de Simone ${ }^{1,2}$, Pietro Campiglia ${ }^{3,4}(\mathbb{0}$, \\ Pietro Formisano ${ }^{1,2}$, Gregory A. Raciti ${ }^{1,2, *}$, Francesco Beguinot ${ }^{1,2, \ddagger}$ and Claudia Miele ${ }^{1,2, *, \ddagger}$ \\ 1 URT Genomics of Diabetes, Institute of Experimental Endocrinology and Oncology, \\ National Research Council, 80131 Naples, Italy; mi.campitelli@gmail.com (M.C.); \\ antonella.desid@gmail.com (A.D.); giuseppe.cacace89@gmail.com (G.C.); cecilia.nigro@alice.it (C.N.); \\ imma.prevenzano@libero.it (I.P.); aleleone86@libero.it (A.L.); sonia.des5309@gmail.com (S.d.S.); \\ fpietro@unina.it (P.F.); beguino@unina.it (F.B.) \\ 2 Department of Translational Medicine, Federico II University of Naples, 80131 Naples, Italy \\ 3 Department of Pharmacy, University of Salerno, 84084 Fisciano, Italy; pcampiglia@unisa.it \\ 4 European Biomedical Research Institute of Salerno, 84125 Salerno, Italy \\ * Correspondence: gregoryalexander.raciti@unina.it (G.A.R.); c.miele@ieos.cnr.it (C.M.); \\ Tel.: +39-081-746-3045 (G.A.R.); +39-081-746-3248 (C.M.) \\ + These authors contributed equally to this work as first authors. \\ $\ddagger$ These authors contributed equally to this work as last authors.
}

Received: 22 April 2020; Accepted: 26 May 2020; Published: 28 May 2020

\begin{abstract}
Citrus aurantium L. dry extracts (CAde) improve adipogenesis in vitro. These effects are dependent from an early modulation of CCAAT/enhancer-binding protein beta $(C / E b p \beta)$ expression and cyclic Adenosine Monophosphate (CAMP) response element-binding protein (CREB) activation. $C / E b p \beta$ and $C r e b$ are also targets of $m i R-155$. This study investigated whether $C A$ de regulates miR-155 expression in the early stages of adipogenesis and whether it ameliorates adipocyte differentiation of cells exposed to tumor necrosis factor-alpha (TNF $\alpha)$. Adipogenic stimuli (AS) were performed in 3T3-L1 pre-adipocytes treated with $C A d e, T N F \alpha$, or both. Gene and miRNA expression were determined by quantitative real-time PCR. Adipogenesis was evaluated by Oil-Red O staining. $C A$ de treatment enhanced AS effects during the early adipogenesis phases by further down-regulating miR-155 expression and increasing both $C / E b p \beta$ and $C r e b$ mRNA and protein levels. At variance, TNF $\alpha$ inhibited 3T3-L1 adipogenesis and abolished AS effects on miR-155, C/Ebp $\beta$, and Creb expression. However, in cells exposed to TNF $\alpha, C A$ de improved adipocyte differentiation and restored the AS effects on miRNA and gene expression at early time points. In conclusion, this study identified miR-155 down-regulation as part of the mechanism through which CAde enhances adipogenesis of pre-adipocytes in vitro. Furthermore, it provides evidence of $C A$ de efficacy against TNF $\alpha$ negative effects on adipogenesis.
\end{abstract}

Keywords: Citrus aurantium L. dry extracts; miR-155; tumor necrosis factor-alpha; adipogenesis

\section{Introduction}

Adipocyte differentiation is a highly orchestrated physiological process, which involves a large number of molecular events and whose dysregulation is relevant to human disease by contributing metabolic dysfunction in obesity [1,2]. microRNAs (miRNAs) represent a class of small non-coding RNAs $(\approx 22 \mathrm{nt}$ in length) involved in a variety of cellular processes, whose role is to repress target 
translation and to induce target mRNA degradation [3]. Oskowitz et al. were the first to detail miRNA expression during human multipotent stromal cell differentiation toward adipogenic lineage and to demonstrate that adipogenic differentiation and lipid accumulation of these cells is disrupted by inhibition of miRNA biogenesis [4]. In the decade that followed, several miRNAs have been implicated in adipocyte fate determination and adipocyte formation from precursor cells; some of them appear to enhance, while some others appear to inhibit adipocyte differentiation [4-18]. For instance, $m i R-27 a$ and $-27 b$, belonging to the $m i R-27$ gene family, were identified as negative regulators of adipogenesis $[7,10,11]$. The expression of both is indeed down-regulated during adipogenic differentiation of 3T3-L1 cells, and their over-expression is inhibited in vitro adipocyte formation by reducing the levels of master adipogenic regulators such as peroxisome proliferator-activated receptor gamma $(P P A R \gamma)$ and CCAAT/enhancer-binding protein alpha (C/EBP $\alpha)$ [7]. miR-130 suppresses adipogenesis by directly targeting and inhibiting PPAR $\gamma$ expression [17], while miR-375 enhances adipocyte differentiation via suppression of extracellular signal-regulated kinases (ERK 1/2) signaling [18].

miR-155, initially described as the B-cell integration (bic) cluster gene in chickens [19], is a multifunctional miRNA involved in numerous physiological and pathological processes such as haematopoietic lineage differentiation, immunity, inflammation, cancer, and cardiovascular diseases [20,21]. Its role in the regulation of adipocyte differentiation has also been described [22]. Liu et al. indeed reported that miR-155 expression is down-regulated at the early stage of 3T3-L1 adipogenesis and that its overexpression suppresses adipocyte differentiation by directly targeting the $3^{\prime}$-untranslated regions ( $3^{\prime}$-UTRs) of C/ebp $\beta$ and cyclic Adenosine Monophosphate (cAMP) response element-binding protein ( $\mathrm{Creb}$ ) mRNAs [22]. In addition, it has been identified as the most responsive miRNA to inflammatory stimuli [22,23], and its expression is higher in the adipose tissue of obese compared to normal-weight subjects and correlates with both tumor necrosis factor-alpha (TNF $\alpha)$ expression and body mass index [23]. It follows that the modulation of the miR-155 expression in adipocyte precursor cells may offer new ways to enhance adipose tissue homeostasis during obesity.

Nutraceuticals, which encompass all the substances derived from plants and food sources that provide medical or health benefits, have been described as modulating miRNA expression [24-26]. As well as this, nutraceuticals are known to regulate adipocyte cell line activity [27]. In line with this, we have recently demonstrated the nutraceutical properties of $C A$ de, a dry extract preparation obtained from Citrus aurantium L. (CAde) fruit juice, on the regulation of 3T3-L1 cell adipocyte differentiation and function [28]. CAde enhances in vitro terminal adipocyte differentiation of 3T3-L1 pre-adipocytes in terms of increased gene expression of Ppar $\gamma$, glucose transporter type 4 (Glut4), and fatty acid-binding protein 4 (Fabp4), as well as the functional capacity of 3T3-L1 mature adipocytes in terms of improved insulin-induced glucose uptake [28]. Furthermore, CAde promotes the early differentiation stage as well, by anticipating the 3T3-L1 cell cycle entry and progression during mitotic clonal expansion and by activating $C R E B$ and nearly doubling the expression of the transcription factor $C / E b p \beta$ a few hours later in the adipogenic induction [28].

In the present study, the hypothesis was that miR-155 and the regulation of its expression are the missing pieces that link $C A$ de to $C / E b p \beta$ and $C R E B$ proteins. Furthermore, we also wondered whether $C A$ de might be effective against micro-environmental insults, which affect adipogenesis and $m i R-155$ expression, such as TNF $\alpha$.

\section{Materials and Methods}

\subsection{Citrus aurantium L. Dry Extract (CAde)}

Citrus aurantium L. (CAde) fruit juice dry extracts were from [28]. Lyophilized CAde was re-hydrated with distilled $\mathrm{H}_{2} \mathrm{O}$ to a final concentration of $10 \mathrm{mg} / \mathrm{mL}$ and used for treatments at the concentration of $100 \mu \mathrm{g} / \mathrm{mL}$. 


\subsection{Cell Culture, Adipocyte Differentiation, and Treatments}

Murine embryonic fibroblast 3T3-L1 cells were purchased from the American Type Culture Collection (ATCC, Manassas, VA, USA). Cells were grown and maintained in culture at $37{ }^{\circ} \mathrm{C}$ in a humidified atmosphere of $5 \% \mathrm{CO}_{2}$ in expansion medium consisting of Dulbecco's modified Eagle's medium (DMEM; $4.5 \mathrm{~g} / \mathrm{L}$ glucose; Lonza, Walkersville, MD, USA), 10\% fetal calf serum (FCS; Thermo Fisher Scientific, Waltham, MA, USA), 100 U/mL penicillin (Lonza, Walkersville, MD, USA), and 100 $\mathrm{mg} / \mathrm{mL}$ streptomycin (Lonza, Walkersville, MD, USA) [29,30]. Adipocyte differentiation of 3T3-L1 cells was induced as follows. Cells were grown to confluence in expansion medium. Two days after reaching $100 \%$ confluence (day 0 ), cells were cultured for $48 \mathrm{~h}$ with the adipogenic differentiation medium (AS) consisting of DMEM (4.5 g/L glucose), 10\% fetal bovine serum (FBS, Thermo Fisher Scientific, Waltham, MA, USA), $100 \mathrm{U} / \mathrm{mL}$ penicillin, and $100 \mathrm{mg} / \mathrm{mL}$ streptomycin, supplemented with dexamethasone ( $1 \mu \mathrm{m}$, Sigma Aldrich, St Louis, MO), 3-isobutyl-1-methylxanthine (0.5 mm, Sigma Aldrich, St. Louis, MO, USA), and insulin ( $1 \mu \mathrm{g} / \mathrm{mL}$, Sigma Aldrich, St. Louis, MO, USA). Forty-eight hours later, the medium was changed, and cells were maintained in culture in AS supplemented with $1 \mu \mathrm{g} / \mathrm{mL}$ insulin, replaced every $48 \mathrm{~h}$, until day 8 post-induction. Where indicated, cells were differentiated with CAde (100 $\mu \mathrm{g} / \mathrm{mL})$, or TNF $\alpha$ ( $1 \mathrm{ng} / \mathrm{mL}$; EMD Millipore, Burlington, MA) or both. $C A$ de was added at day 0 and in every replacement. TNF $\alpha$ was added only at day 0 . For short-term experiments, 3T3-L1 cells at day 0 were stimulated for 15, 30, 60, 120, and $240 \mathrm{~min}$ in AS or in AS supplemented with $C A$ de $(100 \mu \mathrm{g} / \mathrm{mL})$, or TNF $\alpha(1 \mathrm{ng} / \mathrm{mL})$ or both.

\section{3. miRNA Mimic and Inhibitor Transfection in Differentiating 3T3-L1}

miRNA mimic and inhibitor transfection were performed according to [31]. Briefly, $100 \%$ confluent 3T3-L1 cells (day 2) were transfected with $5 \mathrm{nmol} \cdot \mathrm{l}^{-1}$ of miRIDIAN mimic mmu-miR-155-5p (C-310430-07-0005, Dharmacon Inc., Lafayette, CO, USA) or $5 \mathrm{nmol} \cdot \mathrm{L}^{-1}$ of the miRIDIAN Hairpin Inhibitor mmu-miR-155-5p (IH-310430-08-0005, Dharmacon Inc.) using Lipofectamine 3000 Reagent (Thermo Fisher Scientific) according to the manufacturer's instructions. The non-targeting control oligonucleotide miRIDIAN microRNA Mimic negative control \#1 (5 nmol. $\mathrm{L}^{-1}$; CN-001000-01-05, Dharmacon Inc.) and the non-targeting control oligonucleotide miRIDIAN microRNA Hairpin Inhibitor negative control \#1 (5 nmol. $\mathrm{L}^{-1}$; IN-001005-01-05, Dharmacon Inc.) were used as a negative control of miRNA mimic and inhibitor transfection, respectively. Forty-eight hours after the transfection (day 0), adipogenesis was induced into cells and left to differentiate into mature adipocytes for a further 8 days, as described above in this section.

\subsection{Image Acquisition, Oil-Red O Staining, and Triglyceride (TG) Quantification Assay}

Images of 3T3-L1 cells at day 8 post-induction were taken using an Olympus microscope system (Olympus, Center Valley, PA, USA). Microphotographs are shown $(\times 10$ magnifications); scale bars, $30 \mu \mathrm{m}$. Oil-Red $\mathrm{O}$ staining was performed as described in [32]. Briefly, 3T3-L1 cells at day 8 post-induction were fixed and stained with Oil-Red O staining solution (Sigma-Aldrich, St. Louis, MO, USA). Lipid accumulation was then quantified by measuring the optical density of the dissolved Oil-Red O staining at $490 \mathrm{~nm}$ by a spectrophotometer. Cellular TG concentration was determined according to [33]. Briefly, 3T3-L1 cells at day 8 post-induction were lysed into PBS $1 \mathrm{X}$ by sonication. TG content per sample was measured using a TG assay kit from Sigma-Aldrich. Per sample DNA was also isolated using the AllPrep DNA/RNA/miRNA Universal Kit (Qiagen, Hilden, Germany), and DNA concentration was quantified and used to normalize data. The values were expressed as $\mu \mathrm{g}$ Triglyceride (TG) $\cdot \mu g$ Deoxyribonucleic acid (DNA) ${ }^{-1}$

\subsection{Total RNA and miRNA Purification, Reverse Transcription, and Quantitative Real-Time PCR}

Total RNA, including miRNA, was isolated from 3T3-L1 cells using AllPrep DNA/RNA/miRNA Universal Kit (Qiagen, Hilden, Germany), according to the manufacturer's instructions. Total RNA 
concentration was quantified with a NanoDrop 2000 spectrophotometer (Thermo Fisher Scientific, Waltham, MA, USA). Gene expression was determined as described [34]. Total RNA (1000 ng) was reverse-transcribed using the SuperScript III Reverse Transcriptase (Qiagen, Hilden, Germany). Gene expression was analyzed by quantitative real-time PCR using the iQ SYBR Green Supermix (Bio-Rad Laboratories, Inc., Hercules, CA, USA) and quantified as relative expression units. Cyclophilin was used as a housekeeping gene. Primer sequences used are the following: $C / E b p \beta F w d$, 5'-cgcccgccgcctttagac-3'; C/Ebp $\beta$ Rev, 5'-cgctcgtgctcgccaatgg-3'; Creb Fwd, 5'-agctgccactcagccgggta-3'; Creb Rev, 5'-tggtgctcgtgggtgctgtg-3'; Cyclophilin Fwd, 5'-gcaagcatgtggtctttggg-3'; Cyclophilin Rev, $5^{\prime}$-gggtaaaatgcccgcaagtc- $3^{\prime}$. miRNA expression was determined as described in [31]. Total RNA (500 ng) was reverse-transcribed using the miScript II RT Kit (Qiagen, Hilden, Germany). miRNA expression was analyzed by quantitative real time-PCR using the miScript SYBR Green PCR Kit (Qiagen, Hilden, Germany) and quantified as relative expression units. U6 small nuclear RNA (snRNA) was used as housekeeping small RNA. Primer sequences were from Qiagen: Mm_miR-155_1 miScript Primer Assay, MS00001701; Mm_miR-130a_1 miScript Primer Assay MS00001547; Mm_miR-375_2 miScript Primer Assay MS00032774; RNU6B_13 miScript Primer Assay, MS00014000.

\subsection{Western Blot (WB) Analysis}

WB analysis was performed as described in [28]. 3T3-L1 cell lysates were obtained by lysing cells in buffer containing $20 \mathrm{~mm}$ Tris- $\mathrm{HCl}, \mathrm{pH}$ 7.5; $5 \mathrm{~mm}$ Ethylenediaminetetraacetic acid (EDTA); $150 \mathrm{~mm} \mathrm{NaCl} ; 1 \%$ Nonidet P40 (NP40), $10 \mu \mathrm{m}$ phenylmethylsulfonyl fluoride (PMSF); $5 \mu \mathrm{g} / \mathrm{mL}$ aprotinin; and $5 \mu \mathrm{g} / \mathrm{mL}$ leupeptin. Protein concentration was determined by Coomassie blue protein assay (Bio-Rad Laboratories, Hercules, CA, USA). Equal amounts of proteins lysates were then analyzed by SDS-PAGE, and then electrophoretically transferred to a Polyvinylidene fluoride (PVDF) membrane. Membranes were probed with antibodies to total CREB (48H2, \#9197; Cell Signaling Technology, Danvers, MA, USA), C/EBP $\beta$ (C-19, sc-150; Santa Cruz Biotechnology, Dallas, TX, USA), and VINCULIN (7F9, sc-73614; Santa Cruz Biotechnology, Dallas, TX, USA), and successively re-probed with secondary mouse or rabbit antibodies (Bio-Rad Laboratories) before signal detection with Enhanced chemiluminescence (ECL) plus (GE Healthcare, Chicago, IL, USA).

\subsection{Statistical Procedures}

Data are given as mean \pm standard error of the mean (SEM). One-way analysis of variance (ANOVA) followed by Bonferroni correction post-hoc test was used for comparisons with three or more groups. Data were analyzed by using the GraphPad Software (version 6.00 for Windows, La Jolla, CA, USA).

\section{Results}

3.1. CAde Down-Regulated the Expression of miR-155 and Enhanced C/Ebp $\beta$ and Creb Levels during the Early Stage of Adipogenesis in 3T3-L1 Cells

To test the hypothesis that $C A$ de may potentially exert its pro-adipogenic effects in vitro by modulating miR-155 expression, the early stage of fat cell differentiation was investigated in 3T3-L1 pre-adipocytes. In control cells, AS induced at $15 \mathrm{~min}$ a $10 \%$ reduction of the miR-155 expression, whose levels remained steadily lowered to about $30 \%-35 \%$ at $30 \mathrm{~min}, 1,2$, and $4 \mathrm{~h}$ upon the adipogenic induction (Figure 1a). In AS + CAde-treated cells, the expression of miR-155 resulted in levels being decreased by $31 \%$ already by $15 \mathrm{~min}$, and its levels further declined by $58 \%$ at $30 \mathrm{~min}, 51 \%$ at $1 \mathrm{~h}$, $54 \%$ at $2 \mathrm{~h}$, and $54 \%$ at $4 \mathrm{~h}$ upon adipogenic induction compared to control cells at time 0 (Figure 1a). Interestingly, compared to AS-treated cells, CAde treatment enhanced the effect of AS on miR-155 down-regulation of by $25 \%-40 \%$ at each time point (Figure 1a and Figure S1a). Additionally, we evaluated $C A$ de effect on $m i R-130 a$ and $m i R-375$, whose role in adipocyte fate determination has already been demonstrated $[17,18]$. In control 3T3-L1 cells, AS caused a time-dependent down-regulation of 
the anti-adipogenic miR-130a (Figure 1b) and up-regulation of the pro-adipogenic miR-375 (Figure 1c) compared to control cells at time 0 . Of note, $C A d e$ treatment did not affect the expression of these two miRNAs. Indeed, in AS + CAde-treated cells, the expression levels of both miR-130a (Figure 1b and Figure S1b) and miR-375 (Figure 1c and Figure S1c) at each time point were comparable to those levels observed in AS-treated control cells. Altogether, these findings suggest that CAde specifically modulated the expression of miR-155 in the early stage of fat cell differentiation.

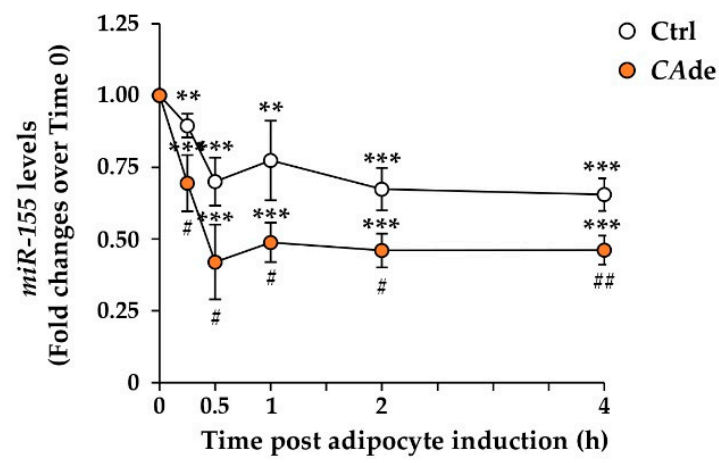

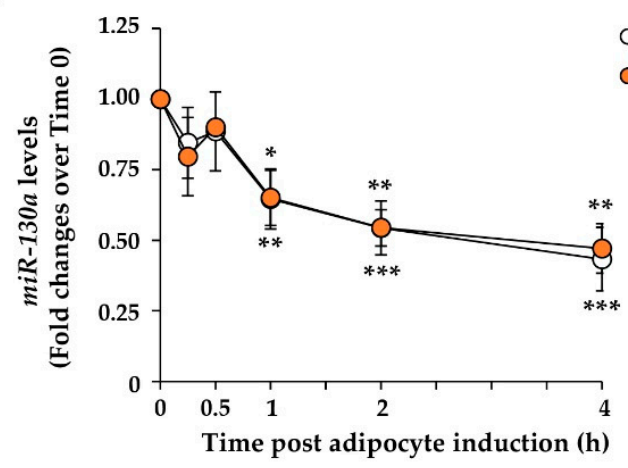

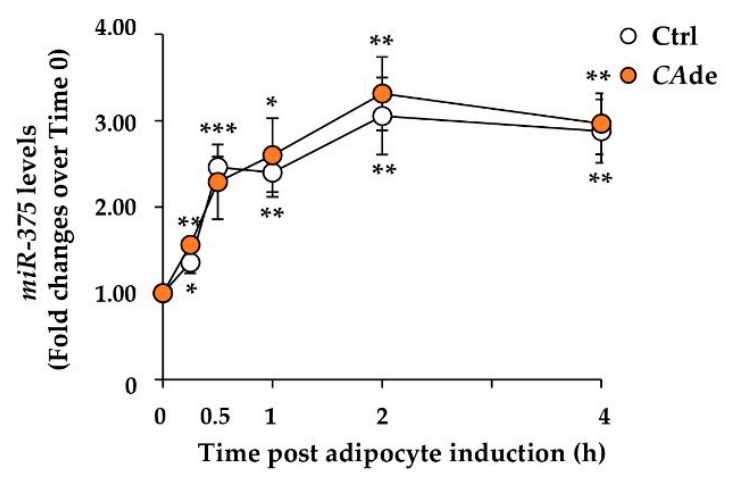

Figure 1. Effect of Citrus aurantium L. dry extracts (CAde) on the expression of miR-155 during the early stage of adipogenesis in 3T3-L1 cells. 3T3-L1 pre-adipocytes were cultured for 0.25, 0.5, 1, 2, and $4 \mathrm{~h}$ with adipogenic differentiation medium (AS) (Ctrl) or AS + CAde $(100 \mu \mathrm{g} / \mathrm{mL})$. Time course of miR-155 (a), $m i R-130 a(\mathbf{b})$, and $m i R-375$ (c) levels, evaluated by quantitative real-time PCR, in Ctrl and CAde-treated cells relative to untreated 3T3-L1 cells at time 0. Values are means \pm Standard Error of the Mean (SEM) of three independent experiments. Control value at time 0 was set as 1.00 . Statistical significances among groups were tested by one-way ANOVA followed by Bonferroni correction post-hoc test $\left({ }^{*} p<0.05\right.$, ${ }^{* *} p<0.01$, and ${ }^{* * *} p<0.001$ vs. untreated 3T3-L1 cells at time 0 ; ${ }^{\#} p<0.05$, and ${ }^{\# \#} p<0.01$ vs. control 3T3-L1 cells).

We thus investigated whether CAde may consequently affect the expression of the miR-155 target genes-C/Ebp $\beta$ and $C r e b$ [21]. In the control cells, AS led to a time-dependent up-regulation of both $C / E b p \beta$ (Figure 2a) and Creb (Figure 2b) mRNA levels compared to control cells at time 0 . It is worth noting that, compared to AS-treated cells, CAde treatment furtherly up-regulated the expression of $C / E b p \beta$ by about $65 \%$ and $45 \%$ at 2 and $4 \mathrm{~h}$, respectively (Figure $2 \mathrm{a}$ and Figure S2a), while the combined stimulation of AS and CAde up-regulated Creb mRNA levels by about $40 \%, 55 \%$, and $25 \%$ at 1,2 , and $4 \mathrm{~h}$, respectively, as compared to treated control cells (Figure $2 \mathrm{~b}$ and Figure S2b). Coherently with the gene expression data, the protein levels of $C / E B P \beta$ isoform liver-enriched activating protein (LAP) resulted as being up-regulated at 2 and $4 \mathrm{~h}$ from AS in CAde-treated cells compared to control cells (Figure 2c). Additionally, the protein levels of $C R E B$ were increased, starting from $0.25 \mathrm{~h}$ from AS in CAde-treated cells (Figure 2c). Altogether, these findings at the early stage of fat cell differentiation indicated that CAde may exert its function on the adipogenic induction in 3T3-L1 cells, at least in part, 
by specifically lowering the expression of $m i R-155$ at the early time points and thus up-regulating the mRNA and protein expression of its target genes $C / E b p \beta$ and $C r e b$.

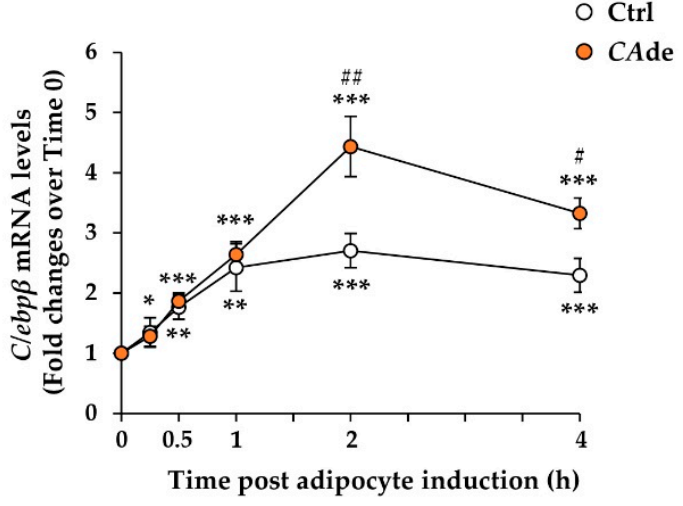

b

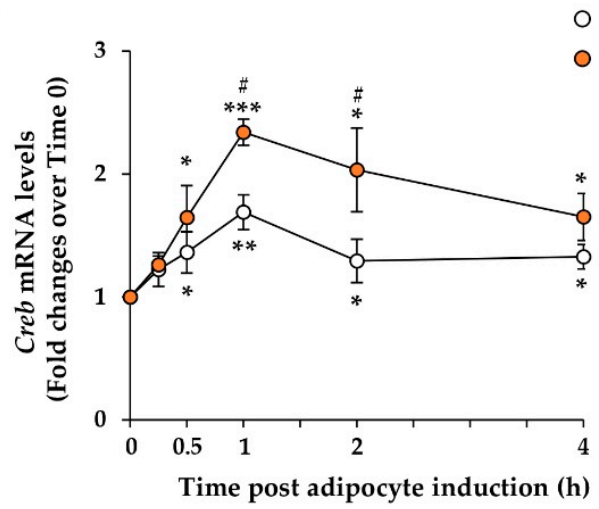

Ctrl

O CAde

C

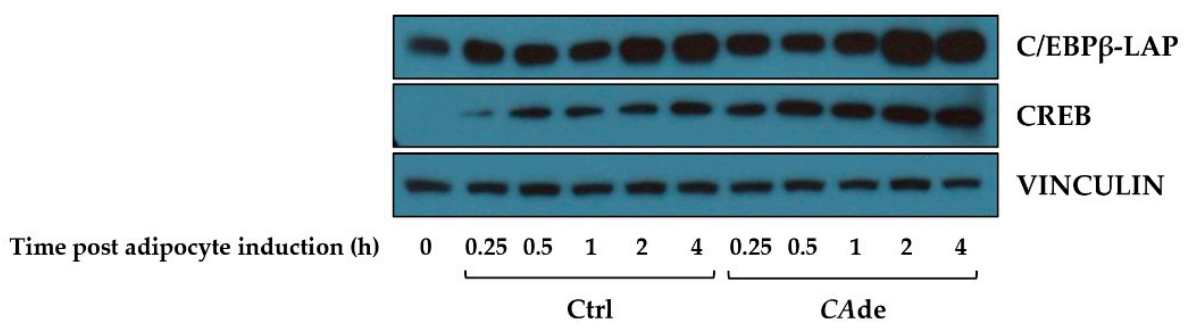

Figure 2. Effect of CAde on the expression of the miR-155 target genes, CCAAT/enhancer-binding protein beta $(C / E b p \beta)$ and cyclic Adenosine Monophosphate (cAMP) response element-binding protein $(\mathrm{Creb})$, during the early stage of adipogenesis in 3T3-L1 cells. 3T3-L1 pre-adipocytes were cultured for $0.25,0.5,1,2$, and $4 \mathrm{~h}$ with AS (Ctrl) or AS + CAde $(100 \mu \mathrm{g} / \mathrm{mL})$. The C/Ebp $\beta$ and Creb levels were evaluated by quantitative real-time PCR. Time course of $C / E b p \beta$ (a) and Creb (b) levels in Ctrl and CAde-treated cells relative to untreated 3T3-L1 cells at time 0 . Values are means \pm SEM of three independent experiments. Control value at time 0 was set as 1.00 . Statistical significances among groups were tested by one-way ANOVA followed by Bonferroni correction post-hoc test $\left(^{*} p<0.05\right.$, ${ }^{* *} p<0.01$, and ${ }^{* * *} p<0.001$ vs. untreated 3T3-L1 cells at time 0 ; ${ }^{\#} p<0.05$ and ${ }^{\# \#} p<0.01$ vs. control 3T3-L1 cells). (c) Representative Western blots of the total form of the C/Ebp $\beta$-liver-enriched activating protein (LAP), CREB, and VINCULIN proteins in control cells and CAde-treated cells at 0.25, 0.5, 1, 2, and $4 \mathrm{~h}$ after adipogenic induction. $\mathrm{C} / \mathrm{Ebp} \beta$-LAP and $C R E B$ protein expression levels at the basal (0) are also reported.

3.2. CAde Improved Terminal Adipocyte Differentiation of Both 3T3-L1 Cells Over-Expressing miR-155 by Mimic Transfection and 3T3-L1 Cells Exposed to TNFa

Over-expression of miR-155, by a gain of function approach [22] or by pro-inflammatory cytokine induction [22,23], has been reported to impair in vitro adipocyte differentiation of 3T3-L1 cells. We then hypothesized that $C A$ de might preserve adipogenesis of 3T3-L1 cells, where miR-155 was over-expressed by mimic transfection or induced by the pro-inflammatory cytokine TNF $\alpha$.

\subsection{1. $m i R-155$ Gain and Loss of Function Studies}

Fat cell differentiation of 3T3-L1 cells was firstly investigated in cells transfected with the miR-155 mimic or the $m i R-155$ inhibitor. The specific over-overexpression of mimic $m i R-155$ reduced the number of 3T3-L1 cells able to differentiate into adipocytes by about $50 \%$, as shown by light microscopy images (Figure 3a) and Oil-Red O lipid accumulation (Figure 3b). In cells treated with CAde, the intracellular lipid accumulation was increased by about 1.4-fold compared to miR-155 over-overexpressing cells 
(Figure $3 \mathrm{a}, \mathrm{b}$ ). On the other hand, the specific loss of function of $m i R-155$ by hairpin inhibitor transfection increased adipogenesis of 3T3-L1 cells by about 90\% (Figure S3); no further increase of adipogenesis was observed in 3T3-L1 cells transfected with miR-155 hairpin inhibitor upon CAde treatment (Figure S3). These findings indicated that CAde treatment partially prevents the inhibitory effects of $m i R-155$ on adipocyte differentiation of 3T3-L1 cells.

a
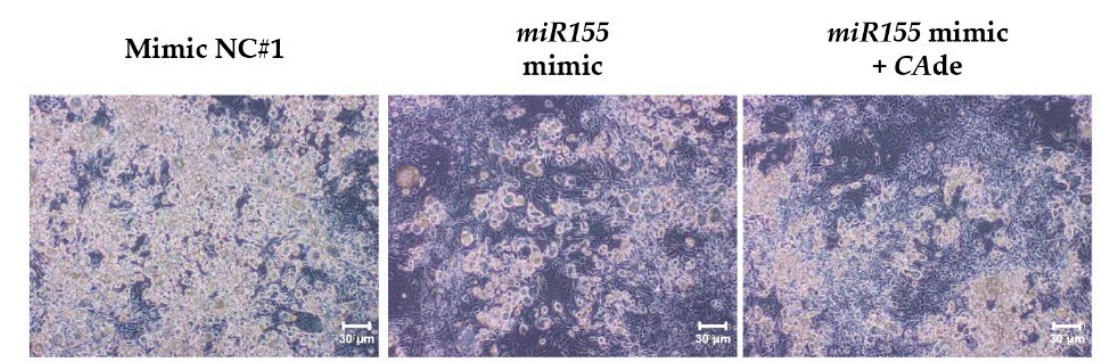

b

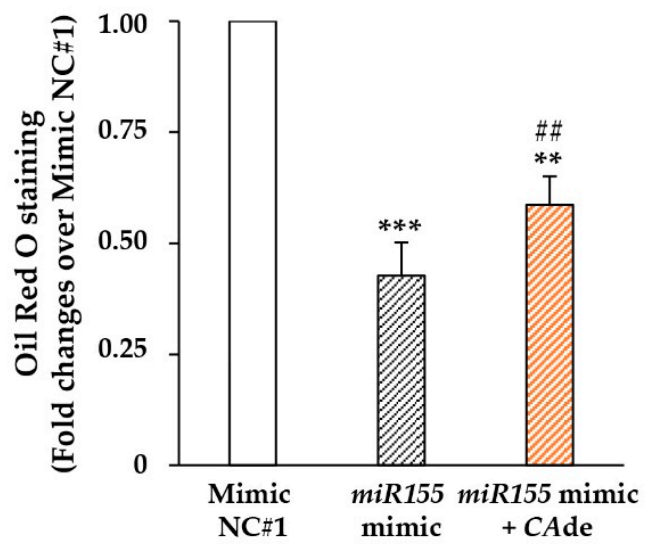

Figure 3. Effect of CAde on adipocyte differentiation and lipid accumulation of 3T3-L1 adipocytes over-overexpressing miR-155. 3T3-L1 pre-adipocytes were transfected with the mimic negative control (NC) \#1 or with the miR-155 mimic, and were cultured to reach adipocyte differentiation for 8 days with AS. Cells transfected with the miR-155 mimic were also differentiated with AS supplemented with $C$ Ade $(100 \mu \mathrm{g} / \mathrm{mL})$. (a) Representative microphotographs of adipocytes transfected with mimic negative control (NC) \#1 or with the miR-155 mimic \pm CAde are shown (X10 magnifications); scale bars, $30 \mu \mathrm{m}$. (b) Oil-Red O staining of adipocytes transfected with mimic negative control (NC) \#1, or with the $m i R-155$ mimic \pm CAde. Values are mean \pm SEM of determinations from three independent experiments. Statistical significances among groups were tested by one-way ANOVA followed by Bonferroni correction post-hoc test ${ }^{* *} p<0.01$, and ${ }^{* * *} p<0.001$ vs. mimic negative control (NC) \#1; \#\# $p<0.01$, miR-155 mimic + CAde vs. miR-155 mimic).

\subsubsection{Treatment with $\mathrm{TNF} \alpha$}

Secondly, we investigated whether CAde may preserve adipogenesis of cells exposed to the pro-inflammatory cytokine $\mathrm{TNF} \alpha$, which exerts profound inhibition of adipocyte differentiation by miR-155 induction [21,22]. As expected, the number of 3T3-L1 pre-adipocytes able to achieve full differentiation was strongly reduced by TNF $\alpha$ treatment, as shown by the light microscopy images (Figure $4 \mathrm{a}$ ). Consistent with this, TNF $\alpha$ reduced the intracellular lipid accumulation (Figure $4 \mathrm{~b}$ ) by about $60 \%$ and the TG deposition by about 70\% (Ctrl, $41.5 \pm 0.3$; TNF $\alpha, 11.2 \pm 0.3, \mu \mathrm{g}$ TG $\cdot \mu \mathrm{g}$ $\left.\mathrm{DNA}^{-1} ; p<0.001\right)$ compared to control adipocytes. It is worth noting that in cells co-treated with TNF $\alpha$ and CAde, the number of adipocytes was increased compared to TNF $\alpha$-treated cells (Figure 4a). In addition, upon CAde treatment, the intracellular lipid accumulation (Figure 4b) and TG deposition were increased by 1.5- and about 2.2-fold, respectively, compared to TNF $\alpha$-treated adipocytes $(\mathrm{TNF} \alpha+$ 
CAde, $\left.26.4 \pm 5.8 ; \mathrm{TNF} \alpha, 11.2 \pm 0.3, \mu \mathrm{g} \mathrm{TG} \cdot \mu \mathrm{g} \mathrm{DNA}{ }^{-1} ; p<0.05\right)$. Altogether, these data suggest that CAde treatment partially protected the adipogenesis of 3T3-L1 cells from the TNF $\alpha$ inhibitory effect.

a

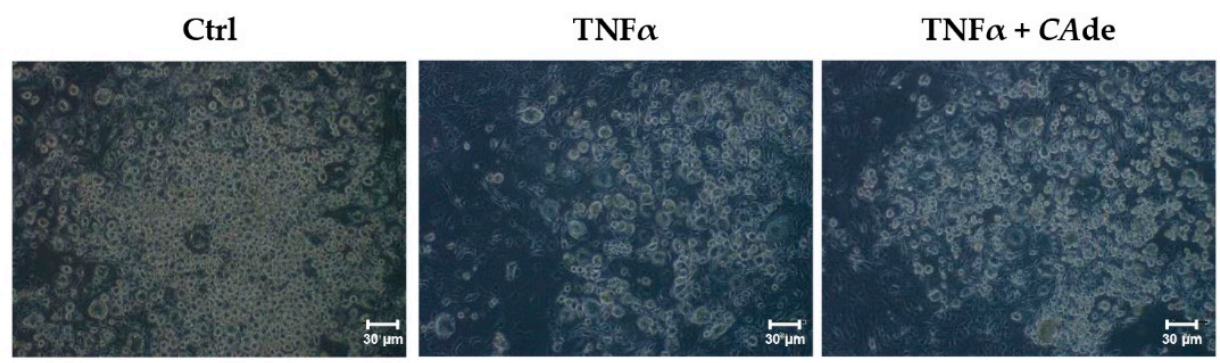

b

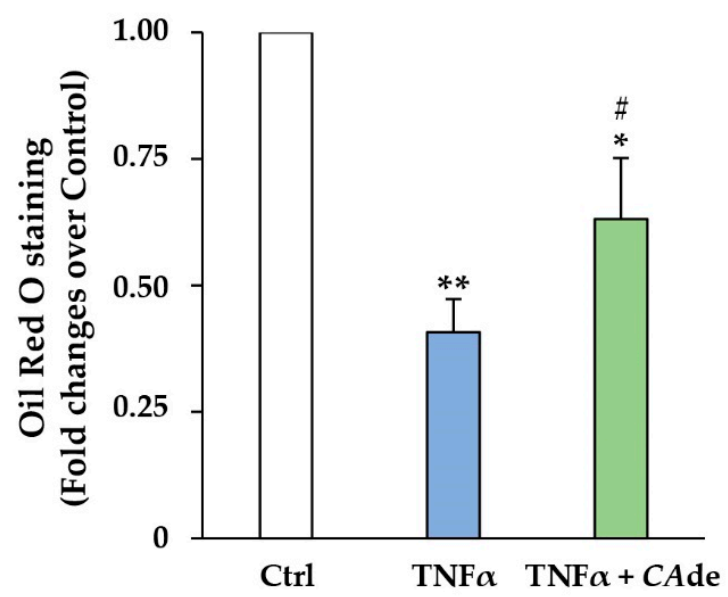

Figure 4. Effect of CAde on adipocyte differentiation and lipid accumulation of 3T3-L1 adipocytes treated with tumor necrosis factor-alpha (TNF $\alpha)$. 3T3-L1 pre-adipocytes were cultured to reach adipocyte differentiation for 8 days with AS (Ctrl) or AS supplemented with TNF $\alpha(1 \mathrm{ng} / \mathrm{mL}) \pm C A$ de $(100 \mu \mathrm{g} / \mathrm{mL})$. (a) Representative microphotographs of $\mathrm{Ctrl}, \mathrm{TNF} \alpha-$, and $\mathrm{TNF} \alpha+C A d e-t r e a t e d ~ a d i p o c y t e s$ are shown (X10 magnifications); scale bars, $30 \mu \mathrm{m}$. (b) Oil-Red O staining of Ctrl, TNF $\alpha$-, and TNF $\alpha+C A$ de-treated adipocytes. Values are mean \pm SEM of determinations from three independent experiments. Statistical significances among groups were tested by one-way ANOVA followed by Bonferroni correction post-hoc test. ( $p<0.05$, and ${ }^{* *} p<0.01$ vs. Ctrl; ${ }^{\#} p<0.05, \mathrm{TNF} \alpha+C A$ de vs. TNF $\alpha$ ).

3.3. CAde Prevented TNF $\alpha$-Induced Dysregulation of miR-155, C/Ebp $\beta$, and Creb Expression during the Early Stage of Adipogenesis in 3T3-L1 Cells

Up-regulation of $m i R-155$ and suppression of $C / E b p \beta$ and $C r e b$ expression were identified as one of the mediators of the TNF $\alpha$-dependent inhibition of adipogenesis [22,23]. We thus evaluated whether $C A$ de may counteract these anti-adipogenic effects of TNF $\alpha$ during the early time points upon adipogenic induction of 3T3-L1 pre-adipocytes. As expected, TNF $\alpha$ already at $15 \mathrm{~min}$ from adipogenic induction induced a 30\% increase in miR-155 expression, whose level remained elevated at $30 \mathrm{~min}, 1,2$, and $4 \mathrm{~h}$ upon AS stimulation compared to control 3T3-L1 cells at time 0 (Figure 5a). Consistent with this, $\mathrm{TNF} \alpha$ treatment also decreased the expression of $C / E b p \beta$ by about $50 \%$ at $30 \mathrm{~min}, 42 \%$ at $1 \mathrm{~h}, 66 \%$ at $2 \mathrm{~h}$, and $35 \%$ at $4 \mathrm{~h}$ upon AS stimulation (Figure $5 \mathrm{~b}$ ) and by Creb by about $52 \%$ at $30 \mathrm{~min}$ and $62 \%$ at $1 \mathrm{~h}$ upon AS stimulation (Figure 5c). Interestingly, the co-treatment with TNF $\alpha$ and CAde down-regulated miR-155 expression during the early time points of adipogenic induction to levels comparable to AS-treated control cells (Figure 5a and Figure S4a). At the same time points upon adipogenic induction, an up-regulation of both $C / E b p \beta$ (Figure $5 b$ and Figure S4b) and $C r e b$ (Figure $5 c$ and Figure S4c) mRNA 
expression, to levels comparable to those in AS-treated control cells, was observed in the TNF $\alpha+$ $C A$ de-treated cells. Altogether, these findings suggest that $C A$ de weakened the inhibitory effect of TNF $\alpha$ on the adipogenesis of 3T3-L1 cells by restoring the AS effects on miR-155 down-regulation and $C / E b p \beta$ and $C r e b$ gene up-regulation at the early differentiation time points.

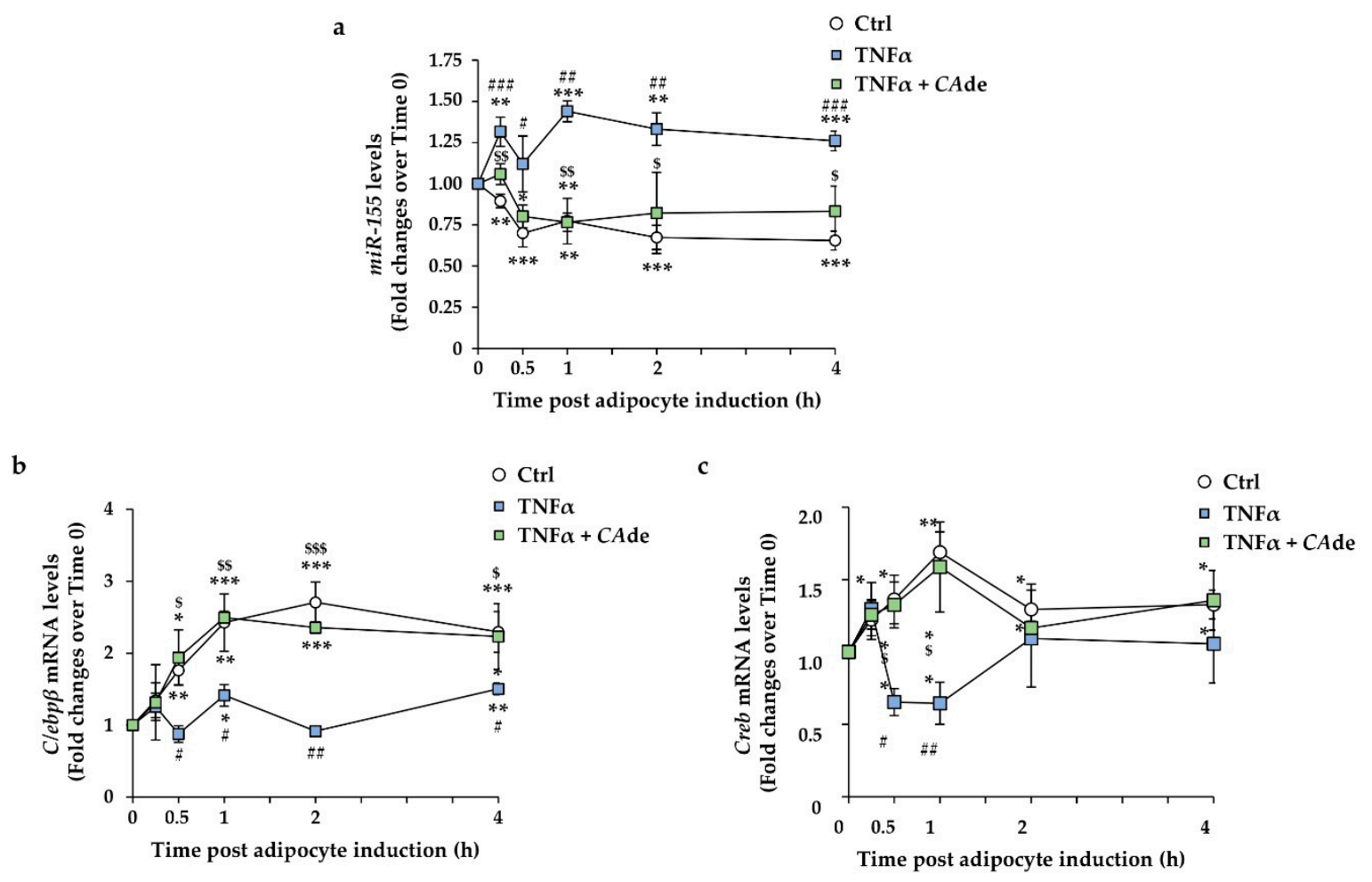

Figure 5. Effect of CAde on the expression of miR-155 and its target genes, C/Ebp $\beta$ and Creb, during the early stage of adipogenesis in 3T3-L1 cells exposed to TNF $\alpha$. 3T3-L1 pre-adipocytes were cultured for $0.25,0.5,1,2$, and $4 \mathrm{~h}$ with AS (Ctrl) or AS supplemented with TNF $\alpha(1 \mathrm{ng} / \mathrm{mL}) \pm C A \mathrm{de}(100 \mu \mathrm{g} / \mathrm{mL})$. The miRNA and gene expressions were evaluated by quantitative real-time PCR. Time course of miR-155 (a), C/Ebp $\beta$ (b), and Creb (c) levels in Ctrl, TNF $\alpha-$, and TNF $\alpha+C A$ de-treated cells are shown relative to untreated 3T3-L1 cells at time 0 . Values are means \pm SEM of three independent experiments. Control value at time 0 was set as 1.00 . Statistical significances among groups were tested by one-way ANOVA followed by Bonferroni correction post-hoc test ${ }^{*} p<0.05,{ }^{* *} p<0.01$, and ${ }^{* *} p<0.001$ vs. untreated 3T3-L1 cells at time $0 ;{ }^{\#} p<0.05,{ }^{\# \#} p<0.01$ and ${ }^{\# \# \#} p<0.001$ vs. control 3T3-L1 cells; ${ }^{\$} p<0.05$, $\$ \$ p<0.01, \$ \$ \$ 0.001$ vs. TNF $\alpha$-treated 3T3-L1 cells).

\section{Discussion}

miRNAs have emerged as critical regulators of a variety of biological processes in eukaryotic cells, and the deregulation of their function is associated with an increasing number of human diseases [3]. Furthermore, it has been reported that miRNAs may contribute to the metabolic abnormalities associated with obesity and obesity-related complications by particularly affecting the function of the white adipose tissue (WAT) [35,36]. Indeed, in human WAT, numerous miRNAs are expressed, obesity influences their expression, and their predominant function is to stimulate or inhibit the differentiation of pre-adipocytes into adipocytes, as well as to regulate specific metabolic and endocrine functions, as revealed through loss or gain of function studies on the obesity-associated miRNAs [35-41]. This makes miRNAs a tangible target for the treatment of adipocyte dysfunction and its related disorders.

Nutraceuticals have been used for decades now in weight management in obese individuals and are described to modulate adipogenesis and to have other positive effects on obesity pathogenesis [27]. Growing evidence sustains the hypothesis that dietary modulation of miRNA expression may explain 
in part some of the beneficial effects of nutraceuticals on health [24-26]. Indeed, an increasing number of studies have reported that several natural food-derived compounds modulate miRNA expression in different animal cells and tissues [24-26]. Extracts from Citrus aurantium L. have been recently used for investigating adipocyte differentiation $[28,42,43]$. However, quite different results have been obtained, and whether or not extracts from Citrus aurantium L. have pro- or anti-adipogenic properties is still unclear. Kim et al. have indeed reported on the anti-adipogenic effect of preparation from the fruit peel of Citrus aurantium L. in 3T3-L1 cells, where the flavonoids naringin, hesperidin, and nobiletin are predominant [42]. Park et al. have instead demonstrated in 3T3-L1 cells and primary cultured adipocytes the anti-adipogenic and pro-thermogenic actions, respectively, of preparation from the immature dried fruit of Citrus aurantium L., which is abundant in naringin and neohesperidin [43]. We have recently shown that $C A d e$, a dry extract preparation obtained from the fruit juice of Citrus aurantium L., mainly enriched in hesperidin, narirutin, and vicenin-2, increased adipocyte differentiation and function of 3T3-L1 cells [28]. Therefore, reasons for these controversial findings could probably be found on the specificity and the amounts of flavonoids within each of these Citrus aurantium $\mathrm{L}$. extracts, which also depends on their origin.

In the present study, we have further reported new evidence that sustains nutraceutical beneficial effects of $C A$ de on the regulation of miRNA expression and function in vitro in 3T3-L1 pre-adipocytes. In particular, we demonstrated that the treatment of cells with $C A$ de enhanced the down-regulation of the adipogenic suppressor miR-155 [22,23], as early as $15 \mathrm{~min}$ upon induction of adipogenesis in 3T3-L1 pre-adipocytes. This results in an up-regulation of the mRNA and protein levels of the miR-155 target genes, $C / E b p \beta$ and $C r e b$ [22]. Specifically, $C A$ de treatment further increased the expression of $C / E b p \beta$ mRNA and of the pro-adipogenic $C / E B P \beta$-LAP protein isoform upon $2 \mathrm{~h}$ from the adipogenic induction [44]. Additionally, $C A d e$ further up-regulated Creb mRNA and protein levels.

It is worth noting that $C A$ de specifically modulated miR-155 expression during the early stage of adipogenesis. Indeed, $C A$ de treatment during the first $4 \mathrm{~h}$ post-adipogenic induction with AS did not affect the expression of other miRNAs, such as miR-130a and miR-375, whose role in adipocyte fate determination has been already demonstrated $[17,18,41]$. miR-155 is biologically relevant to the regulation of adipocyte differentiation, and its perturbation is associated with obesity [22,23]. In addition, miR-155 expression in cells is modulated by nutraceutical compounds [45-47]. Indeed, Eseberri et al. have shown that the stilbenoid resveratrol and its metabolites, trans-resveratrol-3-O-glucuronide and trans-resveratrol-4-O-glucuronide, exert their anti-adipogenic effect on 3T3-L1 cells by up-regulating miR-155 expression [45]. On the contrary, others reported the down-regulation of the same miRNA by flavonoid treatment $[46,47]$. Boesch-Saadatmandi et al. have indeed demonstrated that the flavonoid quercetin and its metabolite isorhamnetin partially neutralize lipopolysaccharide-induced increase of miR-155 in murine RAW264.7 macrophages and state that miR-155 inhibition possibly contributes to the anti-inflammatory properties of both flavonoids [46]. Additionally, Arango et al. have reported that the flavonoid apigenin and a celery-based apigenin-rich diet exert effective anti-inflammatory activity in vivo by reducing expression of $m i R-155$ [47]. As reported above in this section, flavonoids, such as hesperidin, narirutin, and vicenin-2, are very abundant in our dry extract preparation [28] and their presence might be thus responsible for the observed down-regulation of miR-155 expression in CAde-treated cells.

Here, we have also reported that CAde partially preserved adipogenesis of 3T3-L1 cells, where the expression of miR-155 was up-regulated by mimic transfection. CAde did not further enhance adipogenesis of 3T3-L1 cells, where miR-155 activity was abolished by specific hairpin inhibitor. These findings led us to suppose that the treatment with $C A$ de may be effective against any micro-environmental insults, which impair adipocyte differentiation by up-regulation of miR-155. In accordance with this, we indeed found that the CAde treatment counteracted the detrimental effects of TNF $\alpha$ on adipogenesis. Indeed, terminal adipocyte differentiation of 3T3-L1 cells exposed to TNF $\alpha$ was improved by almost $50 \%$ by $C A$ de and was associated with a restoring of the expression of $m i R-155$, $C / E b p \beta$, and $C r e b$ during the early stage of adipogenesis. TNF $\alpha$ is a pleiotropic cytokine that exerts 
homeostatic and pathogenic bioactivities [48]. High TNF $\alpha$ levels are observed in the WAT during obesity, and they have profound effects on adipocyte metabolism by impairing triglyceride synthesis and storage and inhibiting adipocyte differentiation [22]. Liu et al. have also demonstrated in 3T3-L1 pre-adipocytes that $m i R-155$, whose expression is up-regulated by TNF $\alpha$ as early as 5 min via NFkB-p65 (nuclear factor kappa-light-chain-enhancer of activated B cells) binding to the miR-155 promoter, mediates at least in part the TNF $\alpha$-induced suppression of adipogenesis by down-regulating early adipogenic transcription factors [22]. These findings, therefore, provide the first piece of evidence for the efficacy of CAde treatment in vitro against micro-environment insults deleterious for the functional capacity of adipose cells. In this scenario, CAde may ameliorate, in the early stage, the differentiation process by blocking NFKB-p65 into the cytosol and thus preventing the NFkB-p65-mediated transcription of miR-155. This hypothesis was indeed sustained by our preliminary data in 3T3-L1 pre-adipocytes short-term treated with $\mathrm{TNF} \alpha$, where the TNF $\alpha$-induced NFkB-p65 translocation from cytosol to the nucleus was prevented by $C A$ de treatment.

In conclusion, this study demonstrated that $m i R-155$ down-regulation is part of the mechanism through which CAde enhances adipocyte differentiation of pre-adipocytes in vitro. In addition, we herein provide substantial evidence of the efficacy of this nutraceutical compound against micro-environment insults, which are harmful to adipose cell functionality and affect miR-155 expression, such as $\mathrm{TNF} \alpha$, suggesting that the development of CAde-derived compounds may be an effective strategy for the treatment of adipocyte dysfunction and its related disorders.

Supplementary Materials: The following are available online at http://www.mdpi.com/2072-6643/12/6/1587/s1.

Author Contributions: Conceptualization, M.C. and A.D.; formal analysis, M.C., A.D., and G.A.R.; investigation, M.C., A.D., G.C., C.N., I.P., A.L., and S.d.S.; resources, P.C. and F.B.; writing- original draft preparation, M.C., A.D., and G.A.R.; writing-review and editing, P.C., P.F., F.B., and C.M.; visualization, F.B.; supervision, C.M.; project administration, C.M.; funding acquisition, F.B., G.A.R., and C.M. All authors have read and agreed to the published version of the manuscript.

Funding: This research was funded, in part, by the Ministero dell'Istruzione, Università e della Ricerca Scientifica (grants PRIN 2017 and PON “RICERCA E INNOVAZIONE" 2014-2020 E FSC-progetto "Innovative Devices For SHAping the RIsk of Diabetes" (IDF SHARID)-ARS01_01270), by the Regione Campania (POR FESR 2014-2020-Obiettivo specifico 1.2.-Manifestazione di Interesse per la Realizzazione di Technology Platform nell' ambito della Lotta alle Patologie Oncologiche"-Projects COEPICA, RARE PLAT NET and SATIN), by the Consiglio Nazionale delle Ricerche (grant FLAGSHIP Interomics Project ASPIRE), by the Italian Diabete Ricerca Foundation and Eli Lilly Italy (2018-2020), and by the European Foundation for the Study of Diabetes (EFSD)/Boehringer Ingelheim (2018-2020).

Acknowledgments: We thank Giuseppina Ippolito for administrative support and Said Maouali for technical support.

Conflicts of Interest: The authors declare no conflict of interest.

\section{References}

1. Lowe, C.E.; O’Rahilly, S.; Rochford, J.J. Adipogenesis at a glance. J. Cell Sci. 2011, 124, 2681-2686. [CrossRef] [PubMed]

2. Unger, R.H.; Clark, G.O.; Scherer, P.E.; Orci, L. Lipid homeostasis, lipotoxicity and the metabolic syndrome. Biochim. Biophys. Acta Mol. Cell Boil. Lipids 2010, 1801, 209-214. [CrossRef] [PubMed]

3. Gebert, L.; Macrae, I.J. Regulation of microRNA function in animals. Nat. Rev. Mol. Cell Boil. 2018, 20, 21-37. [CrossRef] [PubMed]

4. Oskowitz, A.Z.; Lu, J.; Penfornis, P.; Ylostalo, J.; McBride, J.; Flemington, E.K.; Prockop, D.J.; Pochampally, R. Human multipotent stromal cells from bone marrow and microRNA: Regulation of differentiation and leukemia inhibitory factor expression. Proc. Natl. Acad. Sci. USA 2008, 105, 18372-18377. [CrossRef]

5. Brandão, B.B.; Guerra, B.A.; Mori, M.A. Shortcuts to a functional adipose tissue: The role of small non-coding RNAs. Redox Boil. 2017, 12, 82-102. [CrossRef]

6. Chen, L.; Song, J.; Cui, J.; Hou, J.; Zheng, X.; Li, C.; Liu, L. MicroRNAs regulate adipocyte differentiation. Cell Boil. Int. 2013, 37, 533-546. [CrossRef]

7. Lin, Q.; Gao, Z.; Alarcon, R.M.; Ye, J.; Yun, Z. A role of miR-27 in the regulation of adipogenesis. FEBS J. 2009, 276, 2348-2358. [CrossRef] 
8. Gerin, I.; Bommer, G.T.; McCoin, C.S.; Sousa, K.M.; Krishnan, V.; MacDougald, O.A. Roles for miRNA-378/378* in adipocyte gene expression and lipogenesis. Am. J. Physiol. Endocrinol. Metab. 2010, 299, 198-206. [CrossRef]

9. Singh, S.K.; Bhadra, M.P.; Girschick, H.J.; Bhadra, U. MicroRNAs-Micro in size but macro in function. FEBS J. 2008, 275, 4929-4944. [CrossRef]

10. Karbiener, M.; Fischer, C.; Nowitsch, S.; Opriessnig, P.; Papak, C.; Ailhaud, G.; Dani, C.; Amri, E.Z.; Scheideler, M. MicroRNA miR-27b impairs human adipocyte differentiation and targets PPARgamma. Biochem. Biophys. Res. Commun. 2009, 390, 247-251. [CrossRef]

11. Kim, S.Y.; Kim, A.Y.; Lee, H.W.; Son, Y.H.; Lee, G.Y.; Lee, J.-W.; Lee, Y.S.; Kim, J.B. MiR-27a is a negative regulator of adipocyte differentiation via suppressing PPAR $\gamma$ expression. Biochem. Biophys. Res. Commun. 2010, 392, 323-328. [CrossRef] [PubMed]

12. Tang, Y.-F.; Zhang, Y.; Li, X.-Y.; Li, C.; Tian, W.; Liu, L. Expression of miR-31, miR-125b-5p, and miR-326 in the Adipogenic Differentiation Process of Adipose-Derived Stem Cells. OMICS A J. Integr. Boil. 2009, 13, 331-336. [CrossRef] [PubMed]

13. Sun, F.; Wang, J.; Pan, Q.; Yu, Y.; Zhang, Y.; Wan, Y.; Wang, J.; Li, X.; Hong, A. Characterization of function and regulation of miR-24-1 and miR-31. Biochem. Biophys. Res. Commun. 2009, 380, 660-665. [CrossRef] [PubMed]

14. Ling, H.-Y.; Ou, H.-S.; Feng, S.-D.; Zhang, X.-Y.; Tuo, Q.-H.; Li, L.; Zhu, B.-Y.; Gao, Z.-P.; Tang, C.-K.; Yin, W.-D.; et al. Changes in microRNA (miR) Profile and Effectis of miR-320 in Insulin-Resistant 3T3-L1 Adipocytes. Clin. Exp. Pharmacol. Physiol. 2009, 36, 32-39. [CrossRef] [PubMed]

15. He, A.; Zhu, L.; Gupta, N.; Chang, Y.; Fang, F.-D. Overexpression of Micro Ribonucleic Acid 29, Highly Up-Regulated in Diabetic Rats, Leads to Insulin Resistance in 3T3-L1 Adipocytes. Mol. Endocrinol. 2007, 21, 2785-2794. [CrossRef] [PubMed]

16. Qin, L.; Chen, Y.; Niu, Y.; Chen, W.; Wang, Q.; Xiao, S.; Li, A.; Xie, Y.; Li, J.; Zhao, X.; et al. A deep investigation into the adipogenesis mechanism: Profile of microRNAs regulating adipogenesis by modulating the canonical Wnt/ $\beta$-catenin signaling pathway. BMC Genom. 2010, 11, 320. [CrossRef] [PubMed]

17. Lee, E.K.; Lee, M.J.; Abdelmohsen, K.; Kim, W.; Kim, M.M.; Srikantan, S.; Martindale, J.L.; Hutchison, E.R.; Kim, H.H.; Marasa, B.S.; et al. miR-130 suppresses adipogenesis by inhibiting peroxisome proliferator-activated receptor gamma expression. Mol. Cell. Biol. 2011, 31, 626-638. [CrossRef]

18. $\quad$ Ling, H.-Y.; Wen, G.-B.; Feng, S.-D.; Tuo, Q.-H.; Ou, H.-S.; Yao, C.H.; Zhu, B.-Y.; Gao, Z.-P.; Zhang, L.; Liao, D.-F. MicroRNA-375 promotes 3T3-L1 adipocyte differentiation through modulation of extracellular signal-regulated kinase signalling. Clin. Exp. Pharmacol. Physiol. 2011, 38, 239-246. [CrossRef]

19. Tam, W.; Ben-Yehuda, D.; Hayward, W.S. Bic, a novel gene activated by proviral insertions in avian leukosis virus-induced lymphomas, is likely to function through its noncoding RNA. Mol. Cell. Boil. 1997, 17, 1490-1502. [CrossRef]

20. Alivernini, S.; Gremese, E.; McSharry, C.; Tolusso, B.; Ferraccioli, G.; McInnes, I.B.; Kurowska-Stolarska, M. MicroRNA-155-At the Critical Interface of Innate and Adaptive Immunity in Arthritis. Front. Immunol. 2018, 8. [CrossRef]

21. Faraoni, I.; Antonetti, F.R.; Cardone, J.; Bonmassar, E. MiR-155 gene: A typical multifunctional microRNA. Biochim. Biophys. Acta Mol. Basis Dis. 2009, 1792, 497-505. [CrossRef]

22. Liu, S.; Yang, Y.; Wu, J. TNF $\alpha$-induced up-regulation of $m i R-155$ inhibits adipogenesis by down-regulating early adipogenic transcription factors. Biochem. Biophys. Res. Commun. 2011, 414, 618-624. [CrossRef]

23. Karkeni, E.; Astier, J.; Tourniaire, F.; El-Abed, M.; Romier, B.; Gouranton, E.; Wan, L.; Borel, P.; Salles, J.; Walrand, S.; et al. Obesity-associated Inflammation Induces microRNA-155 Expression in Adipocytes and Adipose Tissue: Outcome on Adipocyte Function. J. Clin. Endocrinol. Metab. 2016, 101, 1615-1626. [CrossRef] [PubMed]

24. McGregor, R.; Seo, D.Y. MiRNAs as Nutritional Targets in Aging. In Molecular Basis of Nutrition and Aging; Elsevier BV: Amsterdam, The Nederlands, 2016; pp. 277-291.

25. García-Segura, L.; Pérez-Andrade, M.; Miranda-Ríos, J. The Emerging Role of MicroRNAs in the Regulation of Gene Expression by Nutrients. J. Nutr. Nutr. 2013, 6, 16-31. [CrossRef]

26. Ross, S.A.; Davis, C.D. The Emerging Role of microRNAs and Nutrition in Modulating Health and Disease. Annu. Rev. Nutr. 2014, 34, 305-336. [CrossRef] [PubMed]

27. Conroy, K.P.; Davidson, I.M.; Warnock, M. Pathogenic obesity and nutraceuticals. Proc. Nutr. Soc. 2011, 70, 426-438. [CrossRef] [PubMed] 
28. Raciti, G.; Fiory, F.; Campitelli, M.; Desiderio, A.; Spinelli, R.; Longo, M.; Nigro, C.; Pepe, G.; Sommella, E.; Campiglia, P.; et al. Citrus aurantium L. dry extracts promote $C / E b p \beta$ expression and improve adipocyte differentiation in 3T3-L1 cells. PLoS ONE 2018, 13, e0193704. [CrossRef]

29. Longo, M.; Spinelli, R.; D’Esposito, V.; Zatterale, F.; Fiory, F.; Nigro, C.; Raciti, G.; Miele, C.; Formisano, P.; Beguinot, F.; et al. Pathologic endoplasmic reticulum stress induced by glucotoxic insults inhibits adipocyte differentiation and induces an inflammatory phenotype. Biochim. Biophys. Acta Bioenerg. 2016, 1863, 1146-1156. [CrossRef]

30. Raciti, G.; Spinelli, R.; Desiderio, A.; Longo, M.; Parrillo, L.; Nigro, C.; D’Esposito, V.; Mirra, P.; Fiory, F.; Pilone, V.; et al. Specific CpG hyper-methylation leads to Ankrd26 gene down-regulation in white adipose tissue of a mouse model of diet-induced obesity. Sci. Rep. 2017, 7, 43526. [CrossRef]

31. Nigro, C.; Mirra, P.; Prevenzano, I.; Leone, A.; Fiory, F.; Longo, M.; Cabaro, S.; Oriente, F.; Beguinot, F.; Miele, C. miR-214-Dependent Increase of PHLPP2 Levels Mediates the Impairment of Insulin-Stimulated Akt Activation in Mouse Aortic Endothelial Cells Exposed to Methylglyoxal. Int. J. Mol. Sci. 2018, 19, 522. [CrossRef]

32. Liu, X.-F.; Bera, T.K.; Kahue, C.; Escobar, T.; Fei, Z.; Raciti, G.; Pastan, I. ANKRD26 and Its Interacting Partners TRIO, GPS2, HMMR and DIPA Regulate Adipogenesis in 3T3-L1 Cells. PLoS ONE 2012, 7, e38130. [CrossRef] [PubMed]

33. Song, Y.; Park, H.J.; Kang, S.N.; Jang, S.-H.; Lee, S.-J.; Ko, Y.-G.; Kim, G.-S.; Cho, J.-H. Blueberry Peel Extracts Inhibit Adipogenesis in 3T3-L1 Cells and Reduce High-Fat Diet-Induced Obesity. PLoS ONE 2013, 8, e69925. [CrossRef] [PubMed]

34. Raciti, G.; Iadicicco, C.; Ulianich, L.; Vind, B.F.; Gaster, M.; Andreozzi, F.; Longo, M.; Teperino, R.; Ungaro, P.; Di Jeso, B.; et al. Glucosamine-induced endoplasmic reticulum stress affects GLUT4 expression via activating transcription factor 6 in rat and human skeletal muscle cells. Diabetologia 2010, 53, 955-965. [CrossRef] [PubMed]

35. Iacomino, G.; Siani, A. Role of microRNAs in obesity and obesity-related diseases. Genes Nutr. 2017, 12, 23. [CrossRef] [PubMed]

36. Arner, P.; Kulyté, A. MicroRNA regulatory networks in human adipose tissue and obesity. Nat. Rev. Endocrinol. 2015, 11, 276-288. [CrossRef]

37. Klöting, N.; Berthold, S.; Kovács, P.; Schön, M.P.; Fasshauer, M.; Ruschke, K.; Stumvoll, M.; Blüher, M. MicroRNA Expression in Human Omental and Subcutaneous Adipose Tissue. PLoS ONE 2009, 4, e4699. [CrossRef]

38. Hilton, C.; Neville, M.J.; Karpe, F. MicroRNAs in adipose tissue: Their role in adipogenesis and obesity. Int. J. Obes. 2012, 37, 325-332. [CrossRef]

39. Neville, M.J.; Collins, J.M.; Gloyn, A.L.; McCarthy, M.I.; Karpe, F. Comprehensive human adipose tissue mRNA and microRNA endogenous control selection for quantitative real-time-PCR normalization. Obesity 2010, 19, 888-892. [CrossRef]

40. Civelek, M.; Hagopian, R.; Pan, C.; Che, N.; Yang, W.-P.; Kayne, P.S.; Saleem, N.K.; Cederberg, H.; Kuusisto, J.; Gargalovic, P.S.; et al. Genetic regulation of human adipose microRNA expression and its consequences for metabolic traits. Hum. Mol. Genet. 2013, 22, 3023-3037. [CrossRef]

41. Son, Y.H.; Ka, S.; Kim, A.Y.; Kim, J.B. Regulation of Adipocyte Differentiation via MicroRNAs. Endocrinol. Metab. 2014, 29, 122-135. [CrossRef]

42. Kim, G.S.; Park, H.J.; Woo, J.-H.; Kim, M.-K.; Koh, P.-O.; Min, W.; Ko, Y.-G.; Kim, C.-H.; Won, C.; Cho, J.-H. Citrus aurantium flavonoids inhibit adipogenesis through the Akt signaling pathway in 3T3-L1 cells. BMC Complement. Altern. Med. 2012, 12, 31. [CrossRef] [PubMed]

43. Park, J.; Kim, H.-L.; Jung, J.; Ahn, K.S.; Kwak, H.J.; Um, Y.J.; Park, J. Bitter Orange (Citrus aurantium Linné) Improves Obesity by Regulating Adipogenesis and Thermogenesis through AMPK Activation. Nutriens 2019, 11, 1988. [CrossRef] [PubMed]

44. Lechner, S.; Mitterberger, M.C.; Mattesich, M.; Zwerschke, W. Role of C/Ebp $\beta$-LAP and C/Ebp $\beta$-LIP in early adipogenic differentiation of human white adipose-derived progenitors and at later stages in immature adipocytes. Differentioation 2013, 85, 20-31. [CrossRef]

45. Eseberri, I.; Lasa, A.; Miranda, J.; Gràcia, A.; Portillo, M.P. Potential miRNA involvement in the anti-adipogenic effect of resveratrol and its metabolites. PLoS ONE 2017, 12, e0184875. [CrossRef] 
46. Saadatmandi, C.B.; Łoboda, A.; Wagner, A.E.; Stachurska, A.; Jozkowicz, A.; Dulak, J.; Döring, F.; Wolffram, S.; Rimbach, G. Effect of quercetin and its metabolites isorhamnetin and quercetin-3-glucuronide on inflammatory gene expression: Role of miR-155. J. Nutr. Biochem. 2011, 22, 293-299. [CrossRef]

47. Arango, D.; Diosa-Toro, M.; Rojas-Hernandez, L.S.; Cooperstone, J.L.; Schwartz, S.J.; Mo, X.; Jiang, J.; Schmittgen, T.D.; Doseff, A.I. Dietary apigenin reduces LPS-induced expression of $m i R-155$ restoring immune balance during inflammation. Mol. Nutr. Food Res. 2015, 59, 763-772. [CrossRef] [PubMed]

48. Kalliolias, G.; Ivashkiv, L.B. TNF biology, pathogenic mechanisms and emerging therapeutic strategies. Nat. Rev. Rheumatol. 2015, 12, 49-62. [CrossRef]

(C) 2020 by the authors. Licensee MDPI, Basel, Switzerland. This article is an open access article distributed under the terms and conditions of the Creative Commons Attribution (CC BY) license (http://creativecommons.org/licenses/by/4.0/). 